\title{
Role of Agriculture in Carbon Emissions and the Future of Food Production Amidst Climate Change
}

\author{
Himanshu Yadav* \\ SKN Agriculture University, Jobner, Rajasthan, India \\ *Corresponding Author: Himanshu Yadav, SKN Agriculture University, Jobner, \\ Rajasthan, India.
}

Received: May 12, 2020

Published: May 31, 2020

(C) All rights are reserved by Himanshu

Yadav.
The speculations and forecasts regarding Climate change and the effects it will have on various populations have left no stone unturned. There have been various studies and there are numerous implications of Global warming on our planet. The projections of Human population by the end of this century, rising sea levels and declining biodiversity are major concerns for the Carbon footprint we leave on Earth. But the most immediate one, and perhaps the one with the maximum impact worldwide will be Food shortage across Continents. This will have major consequences as we rustle between reducing our Carbon footprint and increasing Food production simultaneously as the margin to achieve both without affecting the other is very fine.

As we try to achieve more food production, we need to apply more of almost everything: Water, pesticides, fertilizers, fuel for mechanical purposes, electricity for irrigation systems along with other farm operations. The repercussions of these excess applications are harmful. Over Irrigation leads to shortage of it in drinking. Drinking water is scare anyways and its spillage and erosion creates insurmountable problems. According to World wildlife organisation, 1.1 billion people worldwide lack access to water and 2.7 billion find it scarce for atleast a month of the year. Fertilizers are great in shorter run but in the bigger picture, the nutrient imbalance they create is crippling. Pesticide, when leached out, affect ground water supply and river channels. Fuel requirement has the worst impact as burning of fossil fuel has disastrous effects on Green house gas emissions. The balance of $\mathrm{CO} 2$ in the atmosphere has been distorted to limits. The last time $\mathrm{CO}_{2}$ concentration was at the present level was 3 million years ago. Humans didn't exist back then. Obtaining energy for personal consumption and for irrigation or other farm purposes is the necessary evil. Whether it be nuclear power plant, or coal plant, or a simple fuel burner, they are all corruptors of Climate change. Post Industrial revolution, we've increased our global population from 1 billion in 1800 to 7.5 billion in 2020 . There projections are upto 10 billion by 2050 . So, within 250 years we've multiplied 10 times. Our land, soil, usable water and other resources have stayed the same. Evidently we've manufactured creative ways to use these resources but they are limited. Our desires however, are not.

\section{The relationship between cows and global warming}

The famous notion that cows are a major contributor to global warming has been around for decades now. If we go by the data that is presented in this theory, cows come out on the bad side. What we ignore here is the fact that due to the herbivore nature of cows, biomass produced on pasture landscape is increased 3 folds on an average. As the sigmoid growth curve represents, the lag phase is long, log phase short and the senescence even shorter : cows and other herbivores keep the growth around the lag phase for most of the times and hence contribute in biomass production. Hence, for maximum period of time, keeping carbon fixation in check. Soil fertility is also maintained by manure produced on farms. The manure that is produced by cows and similar herbivores are crucial for nutrient uptake. Fresh Cow manure has N-P-K ratio of 1.5-0.3-0.2 while Sheep manure has 1.2-0.5-0.4. These prove to be very useful and are applied extensively.

This not only meets the crop requirements but also help restore the soil fertility that is lost on account of commercial agriculture. Although the methane released due to flatulation still remains a problem, the dung is still used as a clean fuel and hence compensates for the methane released upto an extent. 
Seth Itzkan, Co-founder and Co-director of Soil4Climate correlated the relationship between Grasslands and Carbon sequestration. The herbivores on these grasslands are more or less responsible for not only restoring the grasslands and hence reducing desertification, but the livestock rearing also leads eventually to mitigating climate change.

Famous scientific farmer Joel Salatin has come up with a very unique and simple method for maximising Biomass production and minimising carbon footprint of cows. His method allows cows to graze the grasses after the grasses have crossed the log phase, just before senescence to keep the grasses for most time on soil and only for a little time in cows rumens. He jokingly says that the cowness of a cow is respected when it feeds on green grass rather than the grains. The meat and milk produced from such well fed cows is said to be better than feed fed cows and then directly slaughtered.

There is still a need for coming up with a more comprehensive method for livestock farming but the current argument that only cows are responsible is not entirely true. Cows are the scapegoat for climate change, for no better choice of words here.

\section{Cleaner energy and Paris agreement}

The Paris Agreement is a ground breaking deal mediated by the United Nations between 195 nations in 2015 to reach a consensus and limit global temperature by the end of the century to 2 degrees above preindustrial levels, while pursuing means to limit the increase to 1.5 degrees. The agreement saw all countries to cut their climate-altering pollution and to strengthen those commitments over time. This also provides a platform to developed nation to assist developing nations in their efforts and creating an environment of healthy exchange of information and techniques between the parties involved. Later, the number rose to 197 as the countries signed the agreement.

Efforts have been made since then to understand and culminate activities better and effectively create a sustainable environment. The agreement insures monitoring, verification and transparency of the governments to its public while at the same time maintaining accountability to the Global community. Countries are required to report their carbon emissions and progress periodically. They also have to set limits for every five years.

In the light of recent events amongst Covid-19, industries, flights and almost all major factors contributing to greenhouse gas emissions have come to a halt. This has lead to significant decrease in pollution. In an interview given to Astrophysicist Neil degrasse Tyson, Scientist Katherine Hayhoe (Director of Climate Centre at Texas Tech University) said that if we could sustain the economy by using clean energy, increasing efficiency and drawing out the present Carbon in the atmosphere, it would only take a few weeks to reach the quarter of the goals set in Paris Agreement. It is only a matter of human will, relentless efforts combined with advancements in technology that we could curb Greenhouse gas emissions.

Shifting from traditional fossil fuel generated energy sources to sources such as solar and wind energies can prove to be poignant. It is a common misconception that the renewable forms of energy are not as efficient and feasible as the traditional forms but this is far from reality. The subsidies on fossilised energies are much higher than on renewable energy sources such as solar energy. So, the higher price is actually paid by the Governments. Due to the recent advancements in technology, solar panels have become cheaper to install and easier to maintain. Solar energy, in tropical regions specially, is abundantly available and can replace petroleum based sources in the future. This will reduce Greenhouse gas emissions up to a significant degree. Solar panels go very well with agriculture as they can be installed in big farms with ease. On smaller farms, they can be installed on roofs. In tropical regions, a day's sunlight can provide ample energy to carry out operations at a steady rate. The need however, for engines can not be fulfilled by solar panels and for that, nuclear energy can be employed. These power sources, combined with resilient efforts towards sustainability, can be used to reduce carbon footprint of farms down to minimal digits and possibly, zero.

\section{Food security}

Agriculture is the base of civilisation. It was due to availability of excess food millenniums ago that people could start doing other jobs than food hunts. They knew that they no longer have to hunt everyday or to devote their entire time just for next meal which lead them to arts and sciences. Their endeavours in arts and sciences then lead to a civilisation. Hence, just knowing that one doesn't have to worry for their immediate next meal works wonders for humanity.

In the present context, Food security is not a problem in developed countries. Majority of populations don't have to worry about food on their tables. The amount and choices are ample. However, 
in developing and under developed countries, the sheer effort to get their next meal is arduous. In some cases, every member of the family who can walk, has to work tiring hours just to make a feable living. Over this already strenuous situation, comes the burden of exponentially rising population and Climate change. The projections are often misinterpreted and it is believed that food will be somehow managed for the people. What bureaucrats lack is gritting duels with truth. Data is accurate and the conclusions are not. So there is an evident link which is missing amidst all the hubbub.

A nation is said to be food secured if they have availability, accessibility and nutritional appropriability. Wealthy nations have all three factors satisfied. It is the developing and under developed countries who have to pay the price. Food is scarcely available, hardly accessible and rarely nutritious, specifically in African nations. Droughts and water shortages are already a major problem in Africa and Asia. The uncertainty and over dependency of Monsoon rains in South Asia have hindered crop cycles for decades due to change in wind patterns and temperature fluctuations. Now, due to rapid change in climate, the conditions are worsening. As I write this from Northern India, in the midst of Covid-19 crisis, the weather has been unpredictable in the last month. Rain and dust storms have been frequent in a season where there should've been steady rise in temperature due to Summer season. The unpredictability of weather has always been an unavoidable circumstance in Agriculture but people have learned to live with it. The problem however, is not as simple as it may seem. Roots of these changes lie in Greenhouse gas emissions and overheating of Climate which creates unusual pressure gradients leading to untimely rainfalls and storms.

It is projected that by 2050 , we would produce $20 \%$ more expensive food and $11 \%$ nutritionally deficient than we grow today. Taking in context the population that is expected to rise, food shortage is not a far fetched phenomenon. Not to mention, the depleting Soil fertility and erosion of soil due to varying climate.

Yuval Noah Harari, author of 'Sapiens: A brief history of humankind' states in his book that there are three problems that human race will face in $21^{\text {st }}$ century: Artificial Intelligence, Nuclear war and Climate change. All three are catastrophic but Climate change would lead to a slower and more painful end than the other two.

\section{Carbon sequestration}

In the recent past, the commercialization of Agriculture has resulted in rapid decline in soil health. Both the quality and top soil depth have suffered. But we need to produce more food now more than ever. Although the climate is changing, Agriculture is supposed to dodge the environmental constraints and bear the load to increase Food production. There are only a few areas in Agricultural Science that can be modified enough to increase production. One of them is enriching Soil Organic Carbon. Increasing Organic matter would increase productivity and increase the filtration of seeping water. More Organic matter would nourish crops and plants. There is however, a point beyond which it will produce adverse effects. Organic matter content in Soil is an area where there has been extensive research in the recent times and it proposes a solution to Global Warming in the form of the interesting concept, Carbon Sequestration. The sensitivity of Soil to its Organic matter is critical. It is predicted by Food and Agricultural Organization of the United Nations that more carbon will be lost to the atmosphere than be sequestered into the soil due to climate change as the process of Carbon sequestration is slow and not optimised to the pace of current urgency to the climate change.

Carbon sequestration of soil is boosted by the plant sinks. These sinks, although short lived, still provide a comprehensive way of extracting the carbon from the atmosphere at a fast rate than they release it back. Grasslands and forests have certainly been the most important aspects of sequestered carbon and continue to do so. Afforestation, hence is answer to most of our problems. But coming to food security for the ever growing population, planting perennial trees does not solve the problem. For this reason, we will have to move towards Sustainable agriculture rather than the century old commercial agriculture. Since industrial revolution, populations have moved towards urban settings. Rural areas have become scarcely populated which means lesser farmers have the responsibility upon themselves which they shared among themselves earlier. Mechanisation does help, but that creates problems of its own. The biggest one being the cost of fuel and maintenance. To manage these costs and several others, a farmer has to move towards commercialising which impacts the soil and crop nutritional quality. The loop continues.

In order to achieve a better resolution, we have to look at the same problems from a new perspective. Addressing century old problems with techniques as old as time may actually be one of the ways to actively fight Climate change. The goal is to switch from subsistence to sustainability. Finding the correct balance between keeping food production feasible and plentiful while at the same time caring for the environmental effects it might have. We can't 
expect farmers to understand the problems their methods incur if there livelihood depends on maximum production with minimum costs. This idea has to change at policy level. World governments have to inculcate in their ideologies the fact that taxation on Carbon emissions, assuming responsibility and factoring over sustainability is the all amassing way to mitigate climate change while assuring Food security.

\section{Assets from publication with us}

- Prompt Acknowledgement after receiving the article

- Thorough Double blinded peer review

- Rapid Publication

- Issue of Publication Certificate

- High visibility of your Published work

Website: www.actascientific.com/

Submit Article: www.actascientific.com/submission.php

Email us: editor@actascientific.com

Contact us: +919182824667 